\title{
Pathogenesis of Helicobacter pylori-Related Gastroduodenal Diseases from Molecular Epidemiological Studies
}

\author{
Yoshio Yamaoka ${ }^{1,2}$ \\ ${ }^{1}$ Department of Environmental and Preventive Medicine, Oita University Faculty of Medicine, 1-1 Idaigaoka, Hasama-machi, \\ Yufu-City, Oita 879-5593, Japan \\ ${ }^{2}$ Department of Medicine-Gastroenterology, Baylor College of Medicine and Michael E. Debakey Veterans Affairs Medical Center, \\ 2002 Holcombe Boulevard, Houston, TX 77030, USA
}

Correspondence should be addressed to Yoshio Yamaoka, yyamaoka@oita-u.ac.jp

Received 16 March 2012; Accepted 27 April 2012

Academic Editor: Ping-I Hsu

Copyright ( 2012 Yoshio Yamaoka. This is an open access article distributed under the Creative Commons Attribution License, which permits unrestricted use, distribution, and reproduction in any medium, provided the original work is properly cited.

Helicobacter pylori is a major human pathogen that infects the stomach and produces inflammation that is responsible for various gastroduodenal diseases. Despite the high prevalence of $H$. pylori infections in Africa and South Asia, the incidence of gastric cancer in these areas is much lower than in other countries. The incidence of gastric cancer also tends to decrease from north to south in East Asia. Data from molecular epidemiological studies show that this variation in different geographic areas could be explained in part by different types of $H$. pylori virulence factors, especially CagA, VacA, and OipA. $H$. pylori infection is thought to be involved in both gastric cancer and duodenal ulcer, which are at opposite ends of the disease spectrum. This discrepancy can also be explained in part by another H. pylori factor, DupA, as well as by CagA typing (East Asian type versus Western type). $H$. pylori has a genome of approximately 1,600 genes; therefore, there might be other novel virulence factors. Because genome wide analyses using whole-genome sequencing technology give a broad view of the genome of $H$. pylori, we hope that next-generation sequencers will enable us to efficiently investigate novel virulence factors.

\section{Introduction}

Helicobacter pylori is a gram-negative spiral bacterium whose ecological niche is the human stomach. It is a major human pathogen that infects the stomach and produces inflammation that is responsible for diseases, such as duodenal ulcer, gastric ulcer, gastric cancer, and mucosaassociated lymphoid tissue lymphoma. Despite a general decline in the incidence of gastric cancer, it remains the fourth most common cancer and second leading cause of cancer-related deaths worldwide (http://globocan.iarc.fr/). Interestingly, despite the high prevalence of $H$. pylori infections in Africa and South Asia, the incidence of gastric cancer in these areas is much lower than in other countries; these phenomena are called African enigmas and Asian enigmas [1] (Table 1). Furthermore, the incidence of gastric cancer has a tendency to decrease from north to south in East Asia. The pathogenesis of the different clinical outcomes is multifactorial with environmental factors (mainly diet) often playing a dominant role and with an influence by host factors, especially those governing the severity of the immune response as well as the virulence of the infecting organism.

$H$. pylori, which is highly heterogeneous, has a genome of approximately 1,600 genes, the majority of which have been functionally characterized, and $5 \%$ to $10 \%$ appear to be $H$. pylori specific $[2,3]$. Genes that are specifically thought to be associated with virulence include vacA, cagA, oipA, and $d u p A$. This paper describes the current knowledge about the pathogenesis of $H$. pylori-related diseases from the aspect of the virulence factors of $H$. pylori.

\section{VacA (Vacuolating Cytotoxin)}

Virtually all $H$. pylori strains have a functional VacA, which encodes a vacuolating cytotoxin. In addition to vacuolation, vacA can induce multiple cellular activities, including membrane channel formation, cytochrome $c$ release from mitochondria leading to apoptosis, and binding to cellmembrane receptors, which is followed by the initiation of 
TABLE 1: Incidence of gastric cancer in 2008.

\begin{tabular}{|c|c|c|c|c|c|c|c|}
\hline \multirow{2}{*}{ Geographic region } & \multirow{2}{*}{ Country } & \multicolumn{2}{|l|}{ Total } & \multicolumn{2}{|l|}{ Male } & \multicolumn{2}{|l|}{ Female } \\
\hline & & Total numbers & ASR & Total numbers & ASR & Total numbers & ASR \\
\hline World total & & 989598 & 14.1 & 640556 & 19.8 & 349042 & 9.1 \\
\hline Asia & & 727500 & 18.6 & 484244 & 25.9 & 243256 & 11.7 \\
\hline East Asia & & 601314 & 30.0 & 408208 & 42.4 & 193106 & 18.3 \\
\hline West Asia & & 14879 & 9.4 & 9248 & 12.6 & 5631 & 6.7 \\
\hline Southeast Asia & & 43281 & 8.6 & 24926 & 10.9 & 18355 & 6.7 \\
\hline South-Central Asia & & 68037 & 5.3 & 41871 & 6.7 & 26166 & 3.9 \\
\hline Latin America and Caribbean & & 65360 & 11.7 & 39401 & 15.7 & 25959 & 8.4 \\
\hline South America & & 47244 & 12.4 & 29312 & 17.3 & 17932 & 8.4 \\
\hline Central America & & 14144 & 10.9 & 7671 & 12.7 & 6473 & 9.3 \\
\hline Caribbean & & 3972 & 8.5 & 2418 & 11.2 & 1554 & 6.1 \\
\hline Europe & & 146939 & 10.3 & 87548 & 14.7 & 59391 & 7.0 \\
\hline Central-East Europe & & 73940 & 14.7 & 43292 & 22.2 & 30648 & 9.7 \\
\hline South Europe & & 32873 & 10.1 & 19953 & 14.0 & 12920 & 6.8 \\
\hline West Europe & & 27457 & 6.5 & 16530 & 9.0 & 10927 & 4.4 \\
\hline North Europe & & 12669 & 6.2 & 7773 & 8.6 & 4896 & 4.2 \\
\hline Oceania & & 2728 & 5.5 & 1746 & 7.5 & 982 & 3.7 \\
\hline North America & & 24401 & 4.2 & 15051 & 5.8 & 9350 & 2.8 \\
\hline Africa & & 22659 & 4.0 & 12557 & 4.7 & 10102 & 3.3 \\
\hline (1) East Asia & South Korea & 27098 & 41.4 & 18200 & 62.2 & 8898 & 24.6 \\
\hline (2) East Asia & Mongolia & 603 & 34.0 & 390 & 48.2 & 213 & 22.3 \\
\hline (3) East Asia & Japan & 102040 & 31.1 & 69561 & 46.8 & 32479 & 18.2 \\
\hline (4) East Asia & China & 464439 & 29.9 & 315843 & 41.3 & 148596 & 18.5 \\
\hline (5) Central America & Guatemala & 2332 & 26.6 & 1123 & 27.3 & 1209 & 25.9 \\
\hline (6) Central America & Honduras & 1245 & 26.6 & 701 & 31.4 & 544 & 22.3 \\
\hline (7) South-Central Asia & Bhutan & 114 & 24.2 & 76 & 31.6 & 38 & 16.2 \\
\hline (8) South America & Ecuador & 3025 & 23.7 & 1667 & 28.0 & 1358 & 19.8 \\
\hline (9) South-Central Asia & Kyrgyzstan & 964 & 23.2 & 619 & 34.2 & 345 & 14.5 \\
\hline (10) Central-East Europe & Belarus & 3527 & 22.5 & 2023 & 34.2 & 1504 & 15.0 \\
\hline (11) Central America & Costa Rica & 946 & 21.8 & 584 & 28.5 & 362 & 15.6 \\
\hline (12) South Europe & Albania & 845 & 21.3 & 459 & 25.4 & 386 & 17.6 \\
\hline (13) South America & Peru & 5215 & 21.2 & 2593 & 22.6 & 2622 & 20.0 \\
\hline (14) South-Central Asia & Kazakhstan & 3329 & 20.6 & 1939 & 31.7 & 1390 & 13.7 \\
\hline (15) West Africa & Mali & 1177 & 20.3 & 567 & 21.6 & 610 & 19.3 \\
\hline (16) South-Central Asia & Tajikistan & 716 & 18.9 & 384 & 22.9 & 332 & 15.6 \\
\hline (17) Southeast Asia & Viet Nam & 15068 & 18.9 & 8429 & 24.4 & 6639 & 14.6 \\
\hline (18) Caribbean & Jamaica & 522 & 18.3 & 318 & 24.9 & 204 & 12.3 \\
\hline (19) South America & Chile & 3762 & 17.9 & 2497 & 27.3 & 1265 & 10.3 \\
\hline (20) Central-East Europe & Russia & 40615 & 17.5 & 22876 & 26.9 & 17739 & 11.7 \\
\hline (21) South America & Colombia & 6638 & 17.4 & 3959 & 23.4 & 2679 & 12.5 \\
\hline (22) West Asia & Azerbaijan & 1428 & 17.3 & 805 & 22.9 & 623 & 12.9 \\
\hline (23) Central-East Europe & Ukraine & 13181 & 16.1 & 7902 & 25.2 & 5279 & 10.3 \\
\hline (24) South-Central Asia & Afghanistan & 1716 & 15.8 & 1036 & 19.5 & 680 & 12.2 \\
\hline (25) South-Central Asia & Iran & 8641 & 15.6 & 6188 & 21.9 & 2453 & 9.0 \\
\hline (26) South-Central Asia & Turkmenistan & 532 & 15.4 & 310 & 21.2 & 222 & 10.9 \\
\hline (27) West Asia & Armenia & 670 & 15.1 & 414 & 23.0 & 256 & 9.6 \\
\hline (28) South Europe & FYR Macedonia & 468 & 15.1 & 315 & 22.7 & 153 & 8.6 \\
\hline (29) North Europe & Lithuania & 916 & 15.0 & 532 & 23.0 & 384 & 10.0 \\
\hline (30) South Europe & Montenegro & 149 & 15.0 & 85 & 19.2 & 64 & 11.5 \\
\hline
\end{tabular}

ASR: age-standardized incidence rates per 100,000 population.

Data are obtained from GLOBOCAN databases, which provide access to the most recent estimates (for 2008) of the incidence of and mortality from 27 major cancers worldwide and is organized by the International Agency for Research on Cancer (IARC) (http://globocan.iarc.fr/).

In addition to the ASR for geographic regions, countries with ASRs that are equal or more than 15.0 for the total (male and female) with total number of gastric cancer more than 100 are listed. 
a proinflammatory response [4-6]. In addition, VacA can specifically inhibit T-cell activation and proliferation [7-9].

Differences in $v a c A$ structure at the signal (s) region ( 1 and $\mathrm{s} 2$ ) and the middle $(\mathrm{m})$ region $(\mathrm{m} 1$ and $\mathrm{m} 2)$ contribute to variations in the vacuolating activity of different $H$. pylori strains [10]. s1/m1 strains are the most cytotoxic, followed by $\mathrm{s} 1 / \mathrm{m} 2$ strains. However, $\mathrm{s} 2 / \mathrm{m} 2$ strains have no cytotoxic activity, and $\mathrm{s} 2 / \mathrm{m} 1$ strains are rare [10]. Many studies in Western countries, including Latin America, the Middle East, and Africa, have shown that individuals who are infected with vacA s1 or $\mathrm{m} 1$ strains have an increased risk of peptic ulcers and/or gastric cancer compared to those infected with s2 or m2 strains [10-12]. In East Asia, most of the $H$. pylori strains possess the vacA s1 genotype; therefore, the type of $s$ region is independent of clinical outcomes $[13,14]$. In contrast, the $\mathrm{m} 1$ genotype is common in areas of Northeast Asia, such as Japan and South Korea, whereas the $\mathrm{m} 2$ genotype is predominant in areas of Southeast Asia, such as Taiwan and Vietnam $[14,15]$. Because the incidence of gastric cancer is higher in the northern regions than in the southern regions of East Asia, the vacA m region may play a role in the regional differences in the disease pattern in East Asia. We recently reported that the vacA $\mathrm{m} 1$ genotype was more prevalent in Hanoi than in Ho Chi Minh City in Vietnam, and the incidence of gastric cancer was higher in Hanoi than in Ho Chi Minh City [16]. These findings support the possibility that the $v a c A$ m region is related to clinical outcomes in East Asia.

Okinawa consists of several small islands $\left(2,276 \mathrm{~km}^{2}\right)$ in southwestern Japan. Although the prevalence of $H$. pylori in Okinawa is not different from other parts of Japan $[8,13]$, the incidence of gastric cancer in Okinawa (6.3 deaths/100,000 population) is the lowest in Japan (mean mortality rate of Japan, 11.8 deaths/100,000 population in 2009) (Center for Cancer Control and Information Services, National Cancer Center, Japan, (http://www.ncc.go.jp/)). Interestingly, most of the $H$. pylori strains possess the vacA s1/m1 genotype in the mainland of Japan (e.g., Kyoto) [14]. However, we recently reported that less than $70 \%$ of the strains possessed the $s 1 / \mathrm{m} 1$ genotype in Okinawa [17]. In that study, we evaluated 337 strains and found that the vacA s1/m2 genotype was significantly prevalent in strains derived from gastritis than those derived from gastric ulcers $(17.3 \%$ versus $7.9 \%$, resp.; $P=0.04$ ). The prevalence of the vacA s $2 / \mathrm{m} 2$ genotype was significantly higher in strains derived from gastritis than those derived from gastric ulcers, duodenal ulcers, and gastric cancer $(22.4 \%$ versus $11.9 \%, 10.5 \%$, and $4.2 \%$, resp.; $P=0.04,0.01$, and 0.04 , resp.). Therefore, even in East Asia in areas where there are many cases with non$\mathrm{s} 1 / \mathrm{m} 1$ strains, both the vacA $\mathrm{s}$ and $\mathrm{m}$ genotypes can be used as markers for $H$. pylori-related diseases.

In 2007, a third disease-related region of $v a c A$, which was named the intermediate (i) region, was identified between the $\mathrm{s}$ region and the $\mathrm{m}$ region [18]. All $\mathrm{s} 1 / \mathrm{m} 1$ strains were classified as i1 type, and all s $2 / \mathrm{m} 2$ strains were classified as i2 type. However, s1/m1 strains were classified as either il or i2 types and il strains were shown to be more pathogenic. In a recent study, a novel intermediate variant (i3) was identified. This variant was often found in Turkish strains (25.7\%) [19].
In the original study [18], it was reported that the vacA i genotype was more effective in determining the risk of gastric cancer than in typing the $s$ region or the $m$ region in Iran. An additional study that was conducted by the same group showed that the vacA i genotype was related to the presence of peptic ulcers in Iraq and Italy [20, 21]. Interestingly, a recent study from Republic of South Korea showed that the polymorphisms at amino acid position 196 of $v a c A$, which is located in the i region, were associated with severe outcomes [22]. However, in our study in East and Southeast Asia, there were no associations between the i region and diseases [23]. In a recent study from Portugal that examined patients with progression to more severe histological diagnoses after a mean of 12.8 years of follow-up, the vacA i genotype did not improve the prediction of progression given by the other vacAloci, as in s and $\mathrm{m}$ regions [24]. More recently, we identified a fourth disease-related region between the $\mathrm{i}$ region and the $m$ region and named it the deletion (d) region [25]. The $\mathrm{d}$ region is divided into $\mathrm{d} 1$ without a deletion and $\mathrm{d} 2$ with a 69 to $81 \mathrm{bp}$ deletion. Our study of Western strains showed that $\mathrm{d} 1$ was a risk factor for gastric mucosal atrophy. However, almost all East Asian strains were classified as $s 1 / i 1 / d 1$. Although the roles of the $i$ and $d$ regions should be investigated in a future study, the genotypes of the s and the $\mathrm{m}$ regions seem to currently serve as good markers of clinical outcomes.

\section{CagA (Cytotoxin-Associated Gene A Product)}

cagA is located at one end of the cag pathogenicity island (PAI), which is an approximately $40 \mathrm{kbp}$ region that is thought to have been incorporated into the $H$. pylori genome by horizontal transfer from an unknown source [26]. The cag PAI encodes a type IV secretion system (T4SS), through which CagA is delivered into host cells [27]. CagA has been reported to interact with various target molecules in host cells, and the best studied is the cytoplasmic Src homology2 domain of Src homology-2 phosphatase (SHP-2), which is known to have oncogenic activity [28]. An animal study that used Mongolian gerbils showed that gastric cancer developed in animals infected with wild-type $H$. pylori, whereas it did not in gerbils infected with isogenic cagA mutants [29, 30]. Another study showed that gastric cancer and other malignant neoplasms occurred in some transgenic mice with an artificially introduced CagA protein [31]. These results provide strong evidence for the role of CagA as a bacteriumderived oncoprotein.

There are 2 types of clinical $H$. pylori isolates: cagA genepositive strains and cagA gene-negative strains. Almost all H. pylori isolates from East Asia are cagA positive, whereas approximately $20 \%$ to $40 \%$ of isolates from Europe and Africa are cagA negative [14]. Therefore, the pathogenic differences in East Asia are difficult to explain only in terms of the presence or absence of cagA alone [13]. In Western countries, however, it has been reported that individuals infected with cagA-positive strains are at a higher risk for peptic ulcer and/or gastric cancer than those infected with cagA-negative strains $[32,33]$. It is interesting to note that 
almost all cagA-positive strains are classified as the vacA s1 strain (either $\mathrm{m} 1$ or $\mathrm{m} 2$ ), whereas almost all cagA-negative strains are classified as the $v a c A s 2 / \mathrm{m} 2$ strain [10].

More than 10 years ago, we first reported that cagA could be mainly classified into 2 types (East Asian type and Western type) according to the sequence located in the $3^{\prime}$ region of cagA $[34,35]$. We initially classified the repeat regions into 2 types, the first repeat and the second repeat, and found that the sequence of the second-repeat region was considerably different between East Asian strains and Western strains [14, 34-36]. Each region contains the Glu-Pro-Ile-Tyr-Ala (EPIYA) motifs, which includes a tyrosine phosphorylation site. Recently, it has been more common to name the firstrepeat regions as EPIYA-A and EPIYA-B segments and the second-repeat region in Western and East Asian strains as EPIYA-C and EPIYA-D segments, respectively [28]. Each CagA sequence was assigned a sequence type that consisted of the names of the EPIYA segments in its sequence (e.g., $A B C$, $\mathrm{ABCC}, \mathrm{ABD}$ ).

In vitro experiments have shown that CagA with an EPIYA-D segment has a higher binding ability for SHP2 than CagA with an EPIYA-C segment [28]. An animal study showed that malignant neoplasms occurred in some East Asian-type CagA-introduced transgenic mice, whereas the frequency of tumors was significantly lower in Westerntype CagA-introduced transgenic mice [37]. In addition, molecular epidemiological studies from Thailand and South Korea showed that individuals infected with East Asiantype $\operatorname{cag} A$ strains have an increased risk of peptic ulcer or gastric cancer compared with those infected with Westerntype cagA strains $[22,38]$. We also recently reported that the different incidences of gastric cancer between Okinawa and mainland Japan might be explained by the high prevalence of Western-type cagA strains in Okinawa compared with other areas of Japan [17]. In our study from Okinawa, the East Asian-type cagA genotype was significantly more prevalent in strains derived from gastric ulcers $(83.2 \%)$ and gastric cancer $(87.5 \%)$ than those derived from gastritis $(60.2 \%)$ $(P<0.001$ and $P=0.01$, resp.). The prevalence of the East Asian-type cagA genotype was also significantly higher in strains derived from gastric ulcers $(83.2 \%)$ and gastric cancer $(87.5 \%)$ than those derived from duodenal ulcer $(64.0 \%)$ $(P=0.001$ and 0.02 , resp.). In contrast, there was no significant difference between the prevalence of East Asiantype $\operatorname{cag} A$ in duodenal ulcers and gastritis $(64.0 \%$ versus $60.2 \%)$. H. pylori infection is thought to be involved in both gastric cancer and duodenal ulcers, which are at the opposite ends of the disease spectrum. According to our results, this discrepancy can be explained in part by the prevalence of East Asian-type $\operatorname{cag} A$, which might be specifically related to the development of gastric cancer. Overall, both in vitro and in vivo (animal and human) data clearly show that East Asiantype CagA is more carcinogenic than Western-type CagA.

However, it should be noted that the incidence of gastric cancer is high in some regions where Western-type CagA is predominant. For example, although Western-type CagA strains have been reported to account for the majority of H. pylori strains in Columbia $[4,39]$, the incidence of gastric cancer there is substantially high (Table 1). These facts cannot be explained by the concept of East Asiantype CagA versus Western-type CagA alone. We published the first report that suggested that the number of secondrepeat regions is associated with gastric cancer both in East Asia (Japan) and in Western countries, including Colombia $[34,35]$. Importantly, our study of $100 \mathrm{H}$. pylori isolates that were derived from patients with simple gastritis (30 isolates were from Columbia and 70 were from the USA, where the incidence of gastric cancer is low (Age-Standardized Rate = 4.1)) showed that $57 \%$ of the isolates from Columbia had 2 EPIYA-C segments, whereas only $4 \%$ of the isolates from the USA had 2 EPIYA-C segments [15]. Several studies have confirmed that the incidence of gastric cancer is significantly higher in patients infected with strains with multiple EPIYAC segments compared with those infected with a single segment in Western countries [34, 35, 40, 41]. In addition, a recent large-scale study showed that a higher number of EPIYA-C repeats was associated with gastric cancer and gastric precancerous lesions, as shown by histological gastric atrophy/metaplastic changes and decreased serum levels of pepsinogen I [42]. The prevalence of $H$. pylori infections is high in Africa, while gastric cancer is uncommon, which is known as the "African Enigma" [43]. However, the incidence of gastric cancer is extremely high in Mali, and the frequency of gastric cancer among women in Mali is higher than in Japan (Table 1). It will be interesting to investigate the cagA genotypes in Mali. Taken together, the number of EPIYA$\mathrm{C}$ segments may explain to some extent the geographic difference in the incidence of gastric cancer in Western countries. Somewhat interestingly, although we first reported that the risk of gastric cancer development in the Japanese population increased when the number of second-repeat regions was 2 compared with 1 , the structure of the second repeat was not $\mathrm{DD}$, but $\mathrm{B}^{\prime} \mathrm{D}$, in which the sequences of $\mathrm{B}^{\prime}$ were more similar to $\mathrm{B}$ than to $\mathrm{D}$ [44]. Recent in vitro data have shown that SHP2 binds EPIYA-B segments and C-terminal Src tyrosine kinase (Csk), which is another important molecule that is involved in intracellular signaling systems and prefers to bind EPIYA-A and EPIYA-B segments [45]. These results might indicate that each EPIYA segment plays a role in gastric pathogenesis, and a larger number of any type of EPIYA segments might be used as a marker for an increasing risk for gastric cancer.

As one goes southward in East Asia, the incidence of gastric cancer becomes lower, and the incidence in Vietnam is half of that in South Korea (Table 1), although most Vietnamese strains (93\%) have been reported to possess the East Asian-type CagA [16]. In addition, most of the strains in both Vietnam and South Korea have only 1 EPIYA-A, EPIYA-B, and EPIYA-D segments [44]. Recently, we reported that the structure of the East Asian-type cagA in Vietnamese strains was slightly different from that of strains from other East Asian countries [16]. Vietnamese strains have a unique 18 bp deletion that is located slightly upstream of the EPIYAA segment, whereas the $39 \mathrm{bp}$ deletion is common in East Asian strains, such as those in Japan and South Korea, and no depletion was identified in Western strains. Further research is necessary to determine whether these subtypes are involved in the pathogenesis of gastric cancer. 


\section{OipA (Outer Inflammatory Protein)}

OipA, which is one of the outer membrane proteins, functions in adhesion [46]. Its functional status is regulated by slipped-strand mispairing that is based on the number of CT dinucleotide repeats in the $5^{\prime}$ region of the genes (switch "on" = functional and switch "off" = nonfunctional) [46]. OipA was initially identified as a proinflammatory response-inducing protein based on the fact that oipAisogenic mutants reduced the induction of interluekin-8 (IL8) from gastric epithelial cell lines [46]. A recent study revealed that OipA has a function of inducing inflammation and actin dynamics through the phosphorylation of multiple signaling pathways that usually interact with cag PAI (CagA)related pathways [47-52].

We previously examined the expression status or presence of multiple virulence factors (cag PAI, vacA, iceA, $o i p A$, and $b a b A)$ in different clinical outcomes [33]. $H$. pylori isolates were obtained from 247 patients in the USA and Colombia. An independent univariate analysis showed that the oipA "on," cag PAI-positive, vacA s1 genotype and the babA-positive type were all related to the risk of duodenal ulcer. However, a multiple logistic regression analysis showed that only the oipA "on" status was an independent determinant predictor of duodenal ulcer from gastritis (adjusted odds ratio (OR), 5.0; 95\% confidence interval $(\mathrm{CI})=2.1-11.9)$. This finding was confirmed in a distinct study that used a nonoverlapping cohort of 200 patients that were examined by an immunoblot analysis for 4 outer-membrane proteins: OipA, BabA, BabB, and SabA [53]. A multiple logistic regression analysis showed that only the OipA-positive status was an independent determinant predictor of gastric cancer versus gastritis $(\mathrm{OR}, 4.8 ; 95 \% \mathrm{CI}=$ 1.4-16.8) and duodenal ulcer versus gastritis (OR, 4.0; 95\% $\mathrm{CI}=1.6-10.2)$. In addition, a challenge of human volunteers with an oipA "on"/whole cag PAI-negative clinical isolate (Baylor strain 100 or ATCC BAA-945) that caused severe inflammation supports this notion [54]. In addition, an in vitro study showed that the oipA mutants did not induce gastric mucosal inflammation in mice that were infected for 12 weeks, whereas cagE mutants did induce mucosal inflammation, although the levels were milder than in the parental strains (cagE is an important component of cag PAI) [55].

The above findings suggest that the presence of OipA is a better marker of severe clinical outcomes than cag PAI. However, it is important to note that clinical isolates that contain the cag PAI typically have an oipA "on" status [33, 53, 56-58] despite the oipA gene being physically located approximately $100 \mathrm{kbp}$ from the cag PAI on the $H$. pylori chromosome. oipA status is also linked to the vacA s region type, and it is further closely linked to the presence of the $b a b A$ gene, which is another virulence factor that codes outer membrane proteins [59]. These linkages of the virulence factors may have a certain biological significance, and they may somehow interact with each other; therefore, it might be better to hypothesize that these factors interact synergistically with each other and induce serious diseases, rather than to discuss which of these factors is the most virulent [15]. It is interesting to note that most East Asian strains are classified as oipA status "on," and the CT-repeat sequences in the signal region of oipA were half-collapsed (e.g., CTGCCTTTCT repeat sequence), suggesting that this may result from an intentional change in the status in the course of evolution of the bacteria in order to prevent the switch from being turned "off" easily [46].

\section{DupA (Duodenal Ulcer Promoting)}

In 2005, we described a novel virulence factor, duodenal ulcer promoting (dupA) gene, which was located in the plasticity region of the $H$. pylori genome [60]. DupA pathogenesis appears to involve the induction of IL-8 production in the antrum, leading to antrum-predominant gastritis, which is a well-recognized characteristic of duodenal ulcer. Additionally, it has been reported that $H$. pylori containing intact dupA induces the IL-12 production of monocytes [61].

As for the molecular epidemiological studies, our initial study of a total of $500 \mathrm{H}$. pylori isolates, including 160 from Japan, 175 from Korea, and 165 from Colombia, showed that the positive rate for $d u p A$ was high in patients with duodenal ulcer and low in patients with gastric cancer, regardless of the patients' nationality ( $42 \%$ versus $9 \%$ on average) [60]. However, several controversial results have been reported worldwide, and an association between the presence of $d u p A$ and gastroduodenal diseases has appeared in some populations but not in others [15, 62]. dupA is generally more prevalent in Western strains than in Asian strains. In a recent review, the worldwide prevalence of $d u p A$ in patients with gastritis was reported to be $44.8 \%$, and this value differed significantly between nationalities/ethnicities; $H$. pylori isolates from South America were significantly more likely to possess $d u p A(79.21 \%(160 / 202))$ than those from East Asian (36.62\% (130/355)), Middle Eastern (40.21\% (39/97)), or European $(43.75 \%(42 / 96))$ countries [63]. The association between $d u p A$ status and disease development is primarily observed in Asian countries, such as China, Korea, Iraq, and North India. Our meta-analysis showed that infection with dupA-positive $H$. pylori increased the duodenal ulcer risk $(\mathrm{OR}, 1.41 ; 95 \% \mathrm{CI}=1.12-1.76)$, particularly in Asian countries (OR, 1.57; 95\% CI $=1.19-$ 2.06), but not in Western countries (OR, 1.09; 95\% CI = 0.73-1.62) [64]. In contrast to the linkage among CagA, VacA, and OipA, most studies showed that there were no relationships between the presence of $d u p A$ and the presence of CagA, VacA, or OipA [64].

There are several possible explanations why the importance of $d u p A$ in gastroduodenal diseases has been controversial among studies. First, the discrepancy could be related to the limitations of the techniques used for detecting the intact $d u p A$ gene. All previous studies evaluated the presence of dupA by polymerase chain reactions and dot blot/Southern hybridization, but DupA proteins were not detected by immunoblot. However, it is well known that there are many cases with frame-shift mutations in $d u p A$. Strains with these mutated sequences are not able to produce intact DupA proteins. Intriguingly, the presence of $d u p A$ without a stop 
codon was more frequently observed in strains from patients with duodenal ulcer than in those from patients with gastritis or gastric cancer [65]. Hussein et al. recently classified a $d u p A$ allele with $1,884 \mathrm{bp}$ as $d u p A 1$ and a truncated version with mutations as $d u p A 2$ [61]. Secondly, recent full-sequenced data of $H$. pylori revealed that the length of $d u p A$ depends on the strains, and the length of the Shi470 and G27 strains has an approximately 600-bp longer open reading frame (approximately 2,500 bp) than that of strain J99, due to the additional $5^{\prime}$ region of $d u p A$. This suggests that $d u p A$ has 2 genotypes according to the location of the signal sequence of the $5^{\prime}$ region (long-type and short type). However, no previous studies took the additional $5^{\prime}$ region into account. Our preliminary data from Okinawa, Japan showed that the long-type $d u p A$ and not the short type $d u p A$ was significantly associated with severe gastroduodenal diseases (unpublished observation). A lack of concern about the $5^{\prime}$ region of $d u p A$ might be one reason for the discrepancies in the previous results. Although it is unknown whether proteins from short type $d u p A$ could be produced and/or functional, these data suggest that only strains that possess the long-type $d u p A$ without frame-shift mutations could be functional. Further analyses of the dupA DNA sequence will be necessary to clarify the significance of intact $d u p A$. Additionally, intact dupA should be detected by measuring DupA protein with immunoblotting techniques.

Finally, $\operatorname{dupA}$ is predicted to form a T4SS with vir genes around $d u p A$ ( $d u p A$ cluster). Three gene clusters that code for T4SS have been recognized in $H$. pylori: a protein translocation system encoded by the cag PAI, a DNA-uptake system encoded by the ComB cluster, and an unknown cluster in the plasticity region [66]. dupA and virB4, which is one of the constituents of T4SS, are highly homologous. dupA and the adjacent 6 vir gene homologs (virB8, B9, B10, B11, virD4, and D2) in the plasticity region were predicted to form the third T4SS [15]. We recently investigated the prevalence of $d u p A$ and vir gene homologs and the associations between the status of $d u p A$ clusters and clinical outcomes in the US population and found that the presence of a complete $d u p A$ cluster increases the duodenal ulcer risk compared with $H$. pylori infection with incomplete $d u p A$ clusters or without the $d u p A$ gene independent of the cag PAI status (adjusted OR, 2.13; 95\% CI $=1.13-4.03$ ) [66]. Therefore, although the causal relationship between the dupA cluster and duodenal ulcer development has not been proven, the presence of a complete dupA cluster and not $d u p A$ alone is associated with duodenal ulcer development. Overall, currently, the presence of a complete $d u p A$ cluster with intact $d u p A$ (long-type without frame-shift mutation) could be a good marker to predict the development of duodenal ulcer. Studies of the plasticity zone are only at the beginning and may be the most attractive area for future investigations.

\section{Detection of Genomic Changes for Clinical Studies}

The rapid advances in sequencing technology have enabled massive sequence comparisons. One of the prospective applications of the new technology to the study of $H$. pylori is the identification of novel virulence factors [67-69]. Wholegenome analyses are useful for the investigation of genetic factors that are related to differences in the virulence among strains. McNamara and El-Omar compared the genome sequences of an isolate that was obtained from a patient with gastric cancer (strain 98-10) and an isolate from a patient with gastric ulcer (strain B128) and determined strainspecific genes of strain 98-10 that were candidate genes associated with gastric cancer [70]. Kawai et al. investigated the evolution of East Asian strains using 20 whole genomes of Japanese, Korean, Amerindian, European, and West African strains [68]. A phylogenetic analysis revealed a greater divergence between the East Asian strains and the Western strains in genes related to virulence factors, especially those related to outer membrane proteins and lipopolysaccharide synthesis enzymes. Genomic changes during infection have also been studied. The whole-genome sequence of strain HPAG1 was determined with the whole-genome shotgun method, and the data obtained were used to design a custom microarray [71]. Genotyping of isolates that were obtained from patients with chronic atrophic gastritis revealed gained and lost genes during the progression of the disease, and whole-genome transcriptional profiling identified genes that were associated with the adaptation of $H$. pylori to chronic atrophic gastritis.

A chronological comparison of the whole genome was performed for 5 sets of $H$. pylori strains from Colombia with isolation intervals of 3 to 16 years using the 454 nextgeneration sequencing technology [72]. A comparison of the genomes revealed single-nucleotide polymorphisms and imported clusters that resulted from recombination, which is frequently found in members of the hop family. Data obtained with the massively parallel sequencing technology provide valuable information on candidates of new virulence factors.

\section{Conclusions}

It is obvious that the 4 virulence factors described in this paper are important. However, because $H$. pylori consists of approximately 1,600 genes, there remains the possibility that additional important pathogenic genes will be identified. The sequencing technology is still advancing. We believe that larger amounts of data will become available at lower costs in the near future, and other important novel virulence factors might be discovered. We must also note that the gastric cancer incidence has been changed remarkably with environmental factors, such as diet (e.g., salt intake) or immigration. Host factors (e.g., gene polymorphisms) and duration of the infection (e.g., early infection with duodenal ulcer and late infection with gastric cancer) should also be taken into account. These various factors are thought to interact in a complex manner with each other in the actual development of diseases. We hope that we will gradually understand the mechanisms underlying how $H$. pylori induces gastric inflammation and leads to severe gastroduodenal diseases, such as gastric cancer, by combining bacterial factors with other factors, such as environmental factors and host factors. 


\section{Conflict of Interests}

The authors declare that they have no competing interests.

\section{Acknowledgments}

This paper is based on work that is supported in part by grants from the National Institutes of Health (DK62813), Grants-in-Aid for Scientific Research from the Ministry of Education, Culture, Sports, Science, and Technology (MEXT) of Japan (22390085 and 22659087), Special Coordination Funds for Promoting Science and Technology from MEXT of Japan, and a Research Fund at the Discretion of the President, Oita University.

\section{References}

[1] H. M. Malaty, "Epidemiology of Helicobacter pylori infection," Best Practice and Research: Clinical Gastroenterology, vol. 21, no. 2, pp. 205-214, 2007.

[2] R. A. Alm, L. S. L. Ling, D. T. Moir et al., "Genomic-sequence comparison of two unrelated isolates of the human gastric pathogen Helicobacter pylori," Nature, vol. 397, no. 6715, pp. 176-180, 1999.

[3] J. F. Tomb, O. White, A. R. Kerlavage et al., "The complete genome sequence of the gastric pathogen Helicobacter pylori," Nature, vol. 388, no. 6642, pp. 539-547, 1997.

[4] J. C. Atherton, "The pathogenesis of Helicobacter pyloriinduced gastro-duodenal diseases," Annual Review of Pathology, vol. 1, pp. 63-96, 2006.

[5] T. L. Cover and S. R. Blanke, "Helicobacter pylori VacA, a paradigm for toxin multifunctionality," Nature Reviews Microbiology, vol. 3, no. 4, pp. 320-332, 2005.

[6] J. G. Kusters, A. H. M. Van Vliet, and E. J. Kuipers, "Pathogenesis of Helicobacter pylori infection," Clinical Microbiology Reviews, vol. 19, no. 3, pp. 449-490, 2006.

[7] M. Boncristiano, S. R. Paccani, S. Barone et al., "The Helicobacter pylori vacuolating toxin inhibits T cell activation by two independent mechanisms," Journal of Experimental Medicine, vol. 198, no. 12, pp. 1887-1897, 2003.

[8] B. Gebert, W. Fischer, E. Weiss, R. Hoffmann, and R. Haas, "Helicobacter pylori vacuolating cytotoxin inhibits $\mathrm{T}$ lymphocyte activation," Science, vol. 301, no. 5636, pp. 1099$1102,2003$.

[9] M. S. Sundrud, V. J. Torres, D. Unutmaz, and T. L. Cover, "Inhibition of primary human $\mathrm{T}$ cell proliferation by Helicobacter pylori vacuolating toxin (VacA) is independent of vacA effects on IL-2 secretion," Proceedings of the National Academy of Sciences of the United States of America, vol. 101, no. 20, pp. 7727-7732, 2004.

[10] J. C. Atherton, P. Cao, R. M. Peek, M. K. R. Tummuru, M. J. Blaser, and T. L. Cover, "Mosaicism in vacuolating cytotoxin alleles of Helicobacter pylori. Association of specific vacA types with cytotoxin production and peptic ulceration," The Journal of Biological Chemistry, vol. 270, no. 30, pp. 17771-17777, 1995.

[11] M. Sugimoto, M. R. Zali, and Y. Yamaoka, "The association of $v a c A$ genotypes and Helicobacter pylori-related gastroduodenal diseases in the Middle East," European Journal of Clinical Microbiology and Infectious Diseases, vol. 28, no. 10, pp. 12271236, 2009.

[12] M. Sugimoto and Y. Yamaoka, "The association of vacA genotype and Helicobacter pylori-related disease in Latin
American and African populations," Clinical Microbiology and Infection, vol. 15, no. 9, pp. 835-842, 2009.

[13] Y. Yamaoka, T. Kodama, O. Gutierrez, J. G. Kim, K. Kashima, and D. Y. Graham, "Relationship between Helicobacter priori iceA, $\operatorname{cag} A$, and vacA status and clinical outcome: studies in four different countries," Journal of Clinical Microbiology, vol. 37, no. 7, pp. 2274-2279, 1999.

[14] Y. Yamaoka, E. Orito, M. Mizokami et al., "Helicobacter pylori in North and South America before Columbus," FEBS Letters, vol. 517, no. 1-3, pp. 180-184, 2002.

[15] Y. Yamaoka, "Mechanisms of disease: Helicobacter pylori virulence factors," Nature Reviews Gastroenterology and Hepatology, vol. 7, no. 11, pp. 629-641, 2010.

[16] T. Uchida, L. T. Nguyen, A. Takayama et al., "Analysis of virulence factors of Helicobacter pylori isolated from a Vietnamese population," BMC Microbiology, vol. 9, article 175, 2009.

[17] O. Matsunari, S. Shiota, R. Suzuki et al., "Association between Helicobacter pylori virulence factors and gastroduodenal diseases in Okinawa, Japan," Journal of Clinical Microbiology, vol. 50, no. 3, pp. 876-883, 2012.

[18] J. L. Rhead, D. P. Letley, M. Mohammadi et al., "A new Helicobacter pylori vacuolating cytotoxin determinant, the intermediate region, is associated with gastric cancer," Gastroenterology, vol. 133, no. 3, pp. 926-936, 2007.

[19] C. Chung, A. Olivares, E. Torres, O. Yilmaz, H. Cohen, and G. Perez-Perez, "Diversity of $v a c A$ intermediate region among Helicobacter pylori strains from several regions of the world," Journal of Clinical Microbiology, vol. 48, no. 3, pp. 690-696, 2010.

[20] N. R. Hussein, M. Mohammadi, Y. Talebkhan et al., "Differences in virulence markers between Helicobacter pylori strains from Iraq and those from Iran: potential importance of regional differences in $H$. pylori-associated disease," Journal of Clinical Microbiology, vol. 46, no. 5, pp. 1774-1779, 2008.

[21] D. Basso, C. F. Zambon, D. P. Letley et al., "Clinical relevance of Helicobacter pylori cagA and vacA gene polymorphisms," Gastroenterology, vol. 135, no. 1, pp. 91-99, 2008.

[22] K. R. Jones, S. Jang, J. Y. Chang et al., "Polymorphisms in the intermediate region of vacA impact Helicobacter pyloriinduced disease development," Journal of Clinical Microbiology, vol. 49, no. 1, pp. 101-110, 2011.

[23] H. Ogiwara, D. Y. Graham, and Y. Yamaoka, "vacA i-Region Subtyping," Gastroenterology, vol. 134, no. 4, p. 1267, 2008.

[24] R. M. Ferreira, C. Figueiredo, C. Bonet et al., "Helicobacter pylorivacA intermediate region genotyping and progression of gastric preneoplastic lesions," American Journal of Gastroenterology, vol. 107, no. 1, pp. 145-146, 2012.

[25] H. Ogiwara, M. Sugimoto, T. Ohno et al., "Role of deletion located between the intermediate and middle regions of the Helicobacter pylorivacA gene in cases of gastroduodenal diseases," Journal of Clinical Microbiology, vol. 47, no. 11, pp. 3493-3500, 2009.

[26] S. Censini, C. Lange, Z. Xiang et al., "cag, a pathogenicity island of Helicobacter pylori, encodes type I-specific and disease-associated virulence factors," Proceedings of the National Academy of Sciences of the United States of America, vol. 93, no. 25, pp. 14648-14653, 1996.

[27] S. Backert and M. Selbach, "Role of type IV secretion in Helicobacter pylori pathogenesis," Cellular Microbiology, vol. 10, no. 8, pp. 1573-1581, 2008.

[28] M. Hatakeyama, "Oncogenic mechanisms of the Helicobacter pylori CagA protein,” Nature Reviews Cancer, vol. 4, no. 9, pp. 688-694, 2004. 
[29] A. T. Franco, D. A. Israel, M. K. Washington et al., "Activation of beta-catenin by carcinogenic Helicobacter pylori," Proceedings of the National Academy of Sciences of the United States of America, vol. 102, no. 30, pp. 10646-10651, 2005.

[30] A. T. Franco, E. Johnston, U. Krishna et al., "Regulation of gastric carcinogenesis by Helicobacter pylori virulence factors," Cancer Research, vol. 68, no. 2, pp. 379-387, 2008.

[31] N. Ohnishi, H. Yuasa, and S. Tanaka, "Transgenic expression of Helicobacter pylori CagA induces gastrointestinal and hematopoietic neoplasms in mouse," Chemtracts, vol. 21, no. 3, pp. 121-123, 2008.

[32] L. J. Van Doorn, C. Figueiredo, R. Sanna et al., "Clinical relevance of the cagA, vacA, and iceA status of Helicobacter pylori," Gastroenterology, vol. 115, no. 1, pp. 58-66, 1998.

[33] Y. Yamaoka, S. Kikuchi, H. M. T. ElZimaity, O. Gutierrez, M. S. Osato, and D. Y. Graham, "Importance of Helicobacter pylori oipA in clinical presentation, gastric inflammation, and mucosal interleukin 8 production," Gastroenterology, vol. 123, no. 2, pp. 414-424, 2002.

[34] Y. Yamaoka, T. Kodama, K. Kashima, D. Y. Graham, and A. R. Sepulveda, "Variants of the 3 ' region of the cagA gene in Helicobacter pylori isolates from patients with different $H$. pylori-associated diseases," Journal of Clinical Microbiology, vol. 36, no. 8, pp. 2258-2263, 1998.

[35] Y. Yamaoka, H. M. T. El-Zimaity, O. Gutierrez et al., "Relationship between the cagA $3^{\prime}$ repeat region of Helicobacter pylori, gastric histology, and susceptibility to low $\mathrm{pH}$," Gastroenterology, vol. 117, no. 2, pp. 342-349, 1999.

[36] Y. Yamaoka, M. S. Osato, A. R. Sepulveda et al., "Molecular epidemiology of Helicobacter pylori: separation of H. pylori from East Asian and non-Asian countries," Epidemiology and Infection, vol. 124, no. 1, pp. 91-96, 2000.

[37] M. Miura, N. Ohnishi, S. Tanaka, K. Yanagiya, and M. Hatakeyama, "Differential oncogenic potential of geographically distinct Helicobacter pylori CagA isoforms in mice," International Journal of Cancer, vol. 125, no. 11, pp. 24972504, 2009.

[38] R. K. Vilaichone, V. Mahachai, S. Tumwasorn, J. Y. Wu, D. Y. Graham, and Y. Yamaoka, "Molecular epidemiology and outcome of Helicobacter pylori infection in Thailand: a cultural cross roads," Helicobacter, vol. 9, no. 5, pp. 453-459, 2004.

[39] D. Kersulyte, A. K. Mukhopadhyay, B. Velapatino et al., "Differences in genotypes of Helicobacter pylori from different human populations," Journal of Bacteriology, vol. 182, no. 11, pp. 3210-3218, 2000.

[40] R. H. Argent, M. Kidd, R. J. Owen, R. J. Thomas, M. C. Limb, and J. C. Atherton, "Determinants and consequences of different levels of CagA phosphorylation for clinical isolates of Helicobacter pylori," Gastroenterology, vol. 127, no. 2, pp. 514523, 2004.

[41] T. Azuma, A. Yamakawa, S. Yamazaki et al., "Correlation between variation of the 3 ' region of the cagA gene in Helicobacter pylori and disease outcome in Japan," Journal of Infectious Diseases, vol. 186, no. 11, pp. 1621-1630, 2002.

[42] S. A. Batista, G. A. Rocha, A. M. C. Rocha et al., "Higher number of Helicobacter pylori CagA EPIYA C phosphorylation sites increases the risk of gastric cancer, but not duodenal ulcer," BMC Microbiology, vol. 11, article 61, 2011.

[43] C. Holcombe, B. A. Omotara, J. Eldridge, and D. M. Jones, " $H$. pylori, the most common bacterial infection in Africa: a random serological study," American Journal of Gastroenterology, vol. 87, no. 1, pp. 28-30, 1992.

[44] Y. Xia, Y. Yamaoka, Q. Zhu, I. Matha, and X. Gao, "A comprehensive sequence and disease correlation analyses for the C-terminal region of CagA protein of Helicobacter pylori," PLoS ONE, vol. 4, no. 11, Article ID e7736, 2009.

[45] M. Selbach, F. E. Paul, S. Brandt et al., "Host cell interactome of tyrosine-phosphorylated bacterial proteins," Cell Host and Microbe, vol. 5, no. 4, pp. 397-403, 2009.

[46] Y. Yamaoka, D. H. Kwon, and D. Y. Graham, “A Mr 34,000 proinflammatory outer membrane protein (oipA) of Helicobacter pylori," Proceedings of the National Academy of Sciences of the United States of America, vol. 97, no. 13, pp. 7533-7538, 2000.

[47] T. Kudo, H. Lu, J. Y. Wu et al., "Pattern of Transcription Factor Activation in Helicobacter pylori-Infected Mongolian Gerbils," Gastroenterology, vol. 132, no. 3, pp. 1024-1038, 2007.

[48] J. Y. Wu, H. Lu, Y. Sun, D. Y. Graham, H. S. Cheung, and Y. Yamaoka, "Balance between polyoma enhancing activator 3 and activator protein 1 regulates Helicobacter pyloristimulated matrix metalloproteinase 1 expression," Cancer Research, vol. 66, no. 10, pp. 5111-5120, 2006.

[49] H. Lu, J. Y. Wu, T. Kudo, T. Ohno, D. Y. Graham, and Y. Yamaoka, "Regulation of interleukin-6 promoter activation in gastric epithelial cells infected with Helicobacter pylori," Molecular Biology of the Cell, vol. 16, no. 10, pp. 4954-4966, 2005.

[50] Y. Yamaoka, T. Kudo, H. Lu, A. Casola, A. R. Brasier, and D. Y. Graham, "Role of interferon-stimulated responsive elementlike element in interleukin-8 promoter in Helicobacter pylori infection," Gastroenterology, vol. 126, no. 4, pp. 1030-1043, 2004.

[51] F. H. Tabassam, D. Y. Graham, and Y. Yamaoka, "OipA plays a role in Helicobacter pylori-induced focal adhesion kinase activation and cytoskeletal re-organization," Cellular Microbiology, vol. 10, no. 4, pp. 1008-1020, 2008.

[52] F. H. Tabassam, D. Y. Graham, and Y. Yamaoka, "Helicobacter pylori activate epidermal growth factor receptor- and phosphatidylinositol 3-OH kinase-dependent Akt and glycogen synthase kinase $3 \beta$ phosphorylation," Cellular Microbiology, vol. 11, no. 1, pp. 70-82, 2009.

[53] Y. Yamaoka, O. Ojo, S. Fujimoto et al., "Helicobacter pylori outer membrane proteins and gastroduodenal disease," Gut, vol. 55, no. 6, pp. 775-781, 2006.

[54] D. Y. Graham, A. R. Opekun, M. S. Osato et al., "Challenge model for Helicobacter pylori infection in human volunteers," Gut, vol. 53, no. 9, pp. 1235-1243, 2004.

[55] Y. Yamaoka, M. Kita, T. Kodama et al., "Helicobacter pylori infection in mice: role of outer membrane proteins in colonization and inflammation," Gastroenterology, vol. 123, no. 6, pp. 1992-2004, 2002.

[56] T. Ando, R. M. Peek, D. Pride et al., "Polymorphisms of Helicobacter pylori HP0638 reflect geographic origin and correlate with cagA status," Journal of Clinical Microbiology, vol. 40, no. 1, pp. 239-246, 2002.

[57] A. Dossumbekova, C. Prinz, J. Mages et al., "Helicobacter pylori HopH (OipA) and bacterial pathogenicity: genetic and functional genomic analysis of hopH gene polymorphisms," Journal of Infectious Diseases, vol. 194, no. 10, pp. 1346-1355, 2006.

[58] P. Lehours, A. Ménard, S. Dupouy et al., "Evaluation of the association of nine Helicobacter pylori virulence factors with strains involved in low-grade gastric mucosa-associated lymphoid tissue lymphoma," Infection and Immunity, vol. 72, no. 2, pp. 880-888, 2004.

[59] S. Fujimoto, O. Olaniyi Ojo, A. Arnqvist et al., "Helicobacter pylori BabA Expression, Gastric Mucosal Injury, and Clinical 
Outcome," Clinical Gastroenterology and Hepatology, vol. 5, no. 1, pp. 49-58, 2007.

[60] H. Lu, P. I. Hsu, D. Y. Graham, and Y. Yamaoka, "Duodenal ulcer promoting gene of Helicobacter pylori," Gastroenterology, vol. 128, no. 4, pp. 833-848, 2005.

[61] N. R. Hussein, R. H. Argent, C. K. Marx, S. R. Patel, K. Robinson, and J. C. Atherton, "Helicobacter pylori dupA is polymorphic, and its active form induces proinflammatory cytokine secretion by mononuclear cells," Journal of Infectious Diseases, vol. 202, no. 2, pp. 261-269, 2010.

[62] Y. Yamaoka, "Roles of the plasticity regions of Helicobacter pylori in gastroduodenal pathogenesis," Journal of Medical Microbiology, vol. 57, no. 5, pp. 545-553, 2008.

[63] N. R. Hussein, "The association of dupA and Helicobacter pylori-related gastroduodenal diseases," European Journal of Clinical Microbiology and Infectious Diseases, vol. 29, no. 7, pp. 817-821, 2010.

[64] S. Shiota, O. Matsunari, M. Watada et al., "Systematic review and meta-analysis: the relationship between the Helicobacter pylori dupA gene and clinical outcomes," Gut Pathogens, vol. 2, no. 1, article 13, 2010.

[65] D. M. M. Queiroz, G. A. Rocha, A. M. C. Rocha et al., "DupA polymorphisms and risk of Helicobacter pylori-associated diseases," International Journal of Medical Microbiology, vol. 301, no. 3, pp. 225-228, 2011.

[66] S. W. Jung, M. Sugimoto, S. Shiota et al., "The intact dupA cluster is a more reliableHelicobacter pylorivirulence marker than dupA alone," Infection and Immunity, vol. 80, no. 1, pp. 381-387, 2012.

[67] W. Fischer, L. Windhager, S. Rohrer et al., "Strain-specific genes of Helicobacter pylori: genome evolution driven by a novel type IV secretion system and genomic island transfer," Nucleic Acids Research, vol. 38, no. 18, pp. 6089-6101, 2010.

[68] M. Kawai, Y. Furuta, K. Yahara et al., "Evolution in an oncogenic bacterial species with extreme genome plasticity: Helicobacter pylori East Asian genomes," BMC Microbiology, vol. 11, article 104, 2011.

[69] M. S. McClain, C. L. Shaffer, D. A. Israel, R. M. Peek, and T. L. Cover, "Genome sequence analysis of Helicobacter pylori strains associated with gastric ulceration and gastric cancer," BMC Genomics, vol. 10, article 13, 2009.

[70] D. McNamara and E. El-Omar, "Helicobacter pylori infection and the pathogenesis of gastric cancer: a paradigm for hostbacterial interactions," Digestive and Liver Disease, vol. 40, no. 7, pp. 504-509, 2008.

[71] J. D. Oh, H. Kling-Bäckhed, M. Giannakis et al., "The complete genome sequence of a chronic atrophic gastritis Helicobacter pylori strain: evolution during disease progression," Proceedings of the National Academy of Sciences of the United States of America, vol. 103, no. 26, pp. 9999-10004, 2006.

[72] L. Kennemann, X. Didelot, T. Aebischer et al., "Helicobacter pylori genome evolution during human infection," Proceedings of the National Academy of Sciences of the United States of America, vol. 108, no. 12, pp. 5033-5038, 2011. 


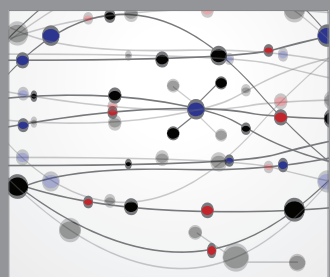

The Scientific World Journal
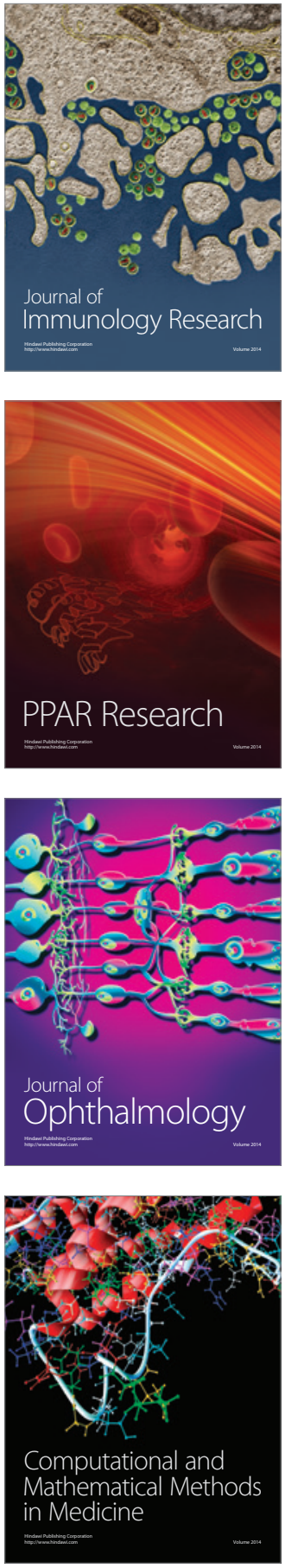

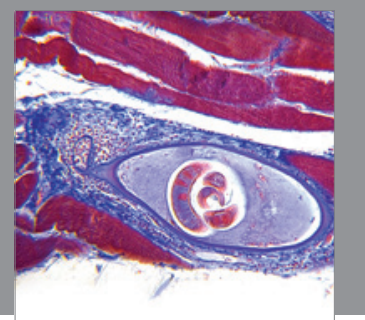

Gastroenterology

Research and Practice
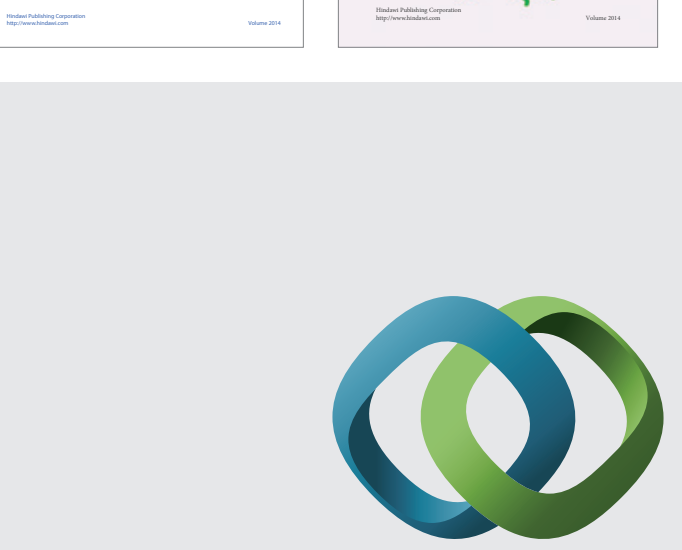

\section{Hindawi}

Submit your manuscripts at

http://www.hindawi.com
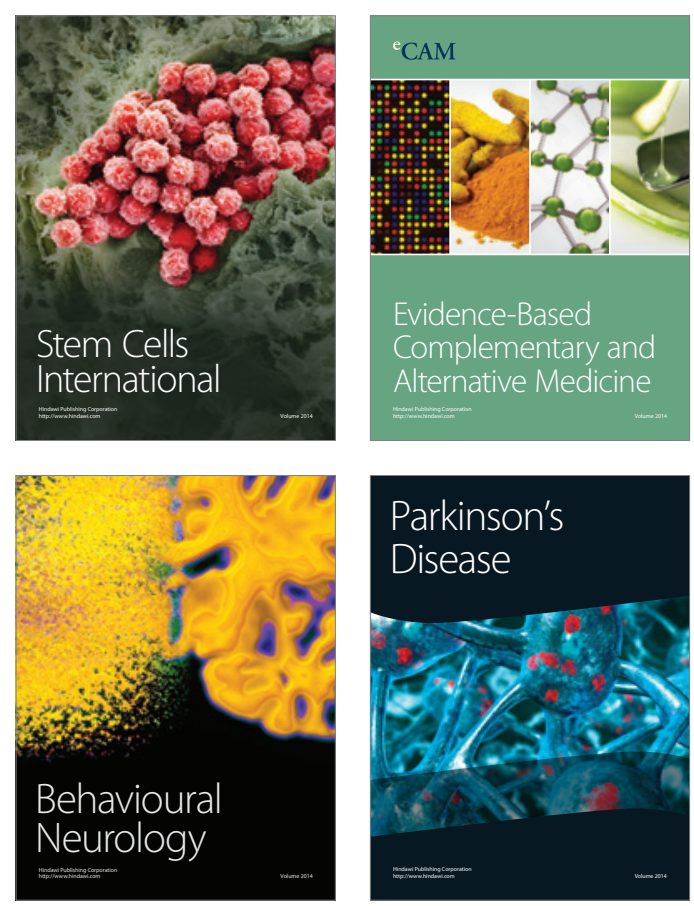

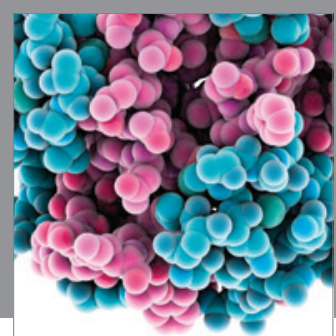

Journal of
Diabetes Research

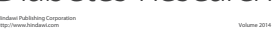

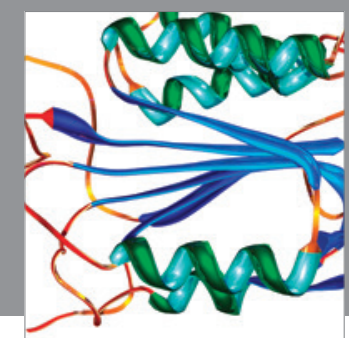

Disease Markers
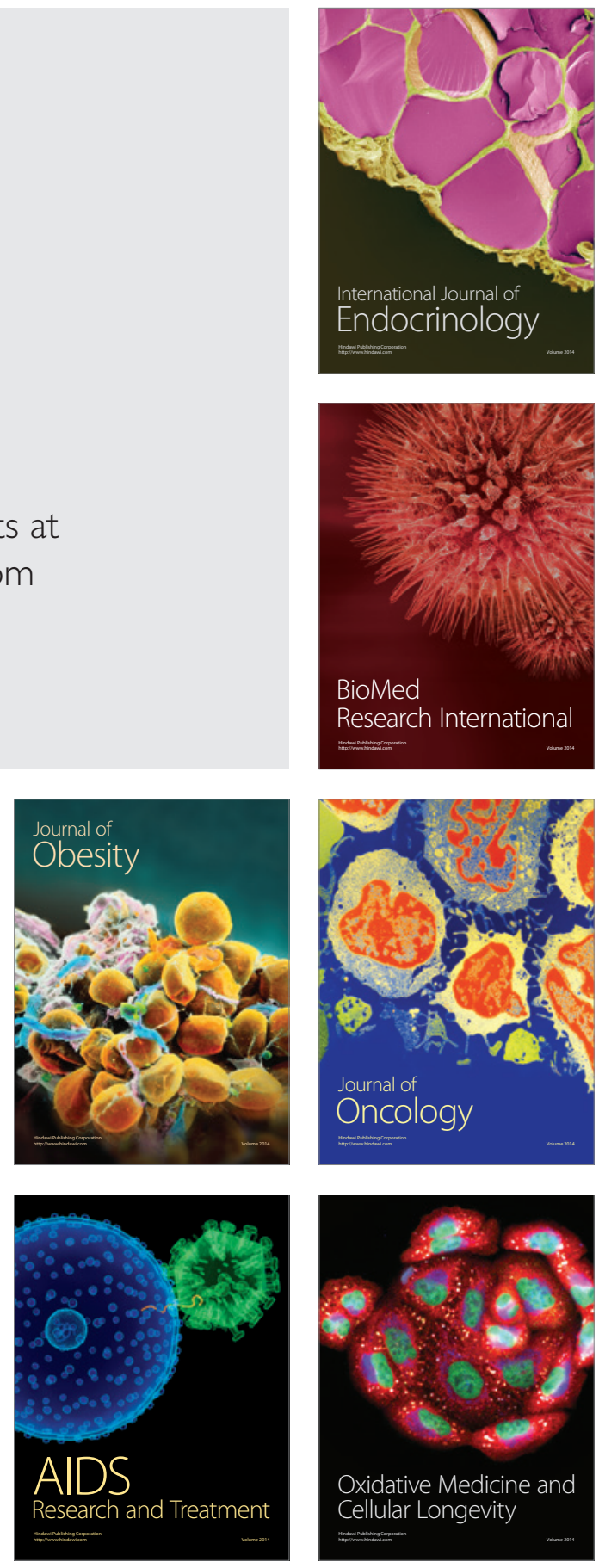